\title{
Intercultural research into the motives of interaction in the "teacher-student" dyad (on the basis of secondary schools in Russia and Tajikistan)
}

\author{
T.S. Shevtsova ${ }^{1 *}$, O.I. Dubrovina ${ }^{2}$, and S.N. Abdurakhmanov ${ }^{3}$ \\ ${ }^{1}$ Tyumen State University, Tyumen, Russia \\ ${ }^{2}$ Tyumen State University, Tyumen, Russia \\ ${ }^{3}$ Lyceum No. 1 for gifted children, Dushanbe, Tajikistan
}

\begin{abstract}
The article presents the results of research into the motives and attitudes of secondary school teachers of in Russia and Tajikistan, as well as educational motivation and motives for teaching students in the Russian and Tadjik secondary schools.
\end{abstract}

\section{A problem statement}

The number of migrants from Tajikistan in Russia, is increasing every year, primarily due to the economic situation. Employable citizens of Tajikistan are forced to arrive with their families due to their long stay in Russia. As Mironova notes, the process of sociocultural adaptation is mediated by the characteristics of migrant children, including: significant gaps in knowledge due to the difference in educational programs, difficulties in understanding the Russian language, differences in the requirements and norms of behavior in schools, and low academic performance; a formed image of a teacher that does not coincide with the real image of a teacher in a Russian secondary school of general education; feelings of anxiety, isolation, and imbalance, as well as the inability to constructively establish contacts with others, to build a dialogue with others, to find their place in society, and the lack the emotional self-regulation techniques that constitute the behavior norms in a new team [1].

In addition, the process of migrant children's adaptation in a general education institution largely depends on a number of internal and external factors. The internal factors include the motivational readiness of a migrant child to accept the norms, values and culture of the host country and to learn its language and traditions. The external factors imply the acceptance of migrants by society, and the extent to which the environment is ready to provide them with help and support. In this case, according to Makarov, teachers of secondary schools can increase the internal motivation of these children and contribute to the creation of more supportive external environment for sociocultural adaptation [2].

Thus, the challenge for a modern teacher is to create a new approach to the lesson management. This approach should be adaptively directed, which would facilitate the

${ }^{*}$ Corresponding author: ipcs-profped@yandex.ru 
process of migrant children's integration into the educational environment. Unfortunately, there is little experience of working with such children in Russia, and teachers are sometimes faced with great difficulties when introducing developmental forms, methods, and teaching aids into the educational process for the migrant children's successful adaptation [3]. So Russian teachers lack understanding of how the image of a teacher is presented in the mind of a child of a different nationality. The Russian teacher is unaware of the specific motivations for the cognitive development of migrant children.

The object of the research is professional interaction in the student-teacher dyad. The subject of the research is the cultural characteristics of the teacher's motivational sphere and the motives of the cognitive development of children. The aim of the research is to study the motives of interaction in the "student-teacher" dyad.

\subsection{The objective of the work}

According to Ainsworth, there are two theoretical perspectives for understanding the adaptation processes of migrants [4]. The first, the classical theory of assimilation, states that with the succession of generations, there is a greater inclusion of persons from a migrant background in the majority group. That is, the longer the family is in the country, the more likely the child is to be fully assimilated into society. In the mid-1960s Gordon wrote about the several stages of assimilation that migrants go through. In his opinion, one can first speak of structural assimilation when a member of an ethnic minority establishes a relationship with the host society. Then comes ethnic identification with the host society. Finally, there should be no prejudice on the part of the majority and non-discrimination against the minority [5].

Already in the 2000s, Alba and Ni specified that the theory was valid only under the conditions that we were talking about a more or less homogeneous in racial and social terms society and active participation of civil institutions in those processes [6]. It is noted in Krushelitskaya's study that "... many migrant children at the age of seven or eight begin to perceive the society in which they are forced to be, as rejecting, humiliating and discriminating. This perception of the situation of one's group in society is known to be a powerful factor provoking the emergence of intergroup hostility" [7].

Over the past 5-10 years, there has been an increase in the families of migrants bringing children to Russia, which is of interest to researchers describing the adaptation processes of migrants [8]. In her works Florinskaya mentions the fears of 'local' children's parents in connection with a decrease in the level of education and communication with state schools [9]. Malyarchuk describes how the hardships and deprivations faced by migrants impact on the adaptation. The very fact of losing their homeland determines the formation of the migrants' life experience of migrants [10]. The cultural shock described manifests itself in the following responses:

- "loss or deprivation of almost all significant objects of life - homeland, status, friends, profession, property" «потери или лишения практически всех значимых объектов жизни - родины, статуса, друзей, профессии, имущества»;

-"anxiety associated with various emotions - surprise, resentment, disgust and indignation - arises in the process of immersion and adaptation to the cultural characteristics of the host country";

- "denial and rejection, such emotions arise when one immerses oneself in someone else's social culture. By alienating themselves from another culture the migrant rejects the culture as a whole ";

- "powerlessness and inferiority, such feelings arise when it is impossible to selfactualize in the process of adaptation to another culture, due to denial and rejection". 
As a result, there is a confusion in values, difficulties in self-identification, and a breakdown in the role structure. The striking manifestations of cultural shock are chronic fatigue and psychosomatic diseases resulting from the intense strain accompanying the migrant's efforts, which are necessary for psychological adaptation. Immersion in a different culture forces migrants to abandon traditional ways of life, adopt different social norms and rules, and change behaviour. The environment itself (nature, climate, food, clothing) often changes, as well as social, economic and psychological relationships with the world and other people, and even relations within the family. But the basic part of the changes, which is most difficult to accept, is related to the cultural code of the country: a different language, values and norms, traditions, customs and rituals" [10].

Invisible, but realistically perceived social boundaries separate migrants from the main non-host society, locking them in solitude in an alien environment, because local residents accept visiting migrants with distrust and fear.

In the light of this situation, a number of authors refer to the importance of intercultural dialogue. T.V. Burkovskaya means that work should be carried out on the basis of intercultural dialogue, taking into account the specific culture of migrant children, their self-awareness, traditions and communication habits acceptable in culture, values, norms and forms of social behavior in society [11]. E.A. Zheleznikova. considers the possibilities of language adaptation of migrants in a modern school. She emphasizes that "in the conditions of joint education of Russian-speaking schoolchildren and children of migrants, it is of great importance to create a system of Russian language courses for migrants" [12].

E.Yu. Zakharchenko draws attention to the fact that the creation of favorable conditions for the migrants' adaptation in an educational organization implies not only the development of communication, the building of intercultural dialogue in a multi-ethnic society, the development of special programs focused on the adaptation of migrant children and the organization of conditions for their education. It also requires training of teachers who come across migrant children, training in the framework of their mastery of several languages and cultures to make them capable of organizing a dialogue of cultures [13].

On the other hand, since the educational process involves the participation of both students and educators, some authors identify factors that affect the motivation of educators of an educational institution and their contribution to the development of migrant schoolchildren as the subject of research [14]. A study by E.B. Demintsev revealed a fairly strong dependence of a migrant child's adaptation on relationships with peers and teachers, as well as on the inclusion of parents in the child's educational process. "The family, as a special social institution, should teach the child to understand the host environment, society, community and culture. Without an example, skills and abilities available for family education, the child is not able to independently overcome the difficulties of the new environment" [8].

Among the studies, one can find works that describe the fundamental possibility of the successful adaptation of migrant children. D.A. Alexandrov, V.V. Baranova, V.A. Ivanyushina presented the results of a large-scale study on the adaptation of children from migrant families in schools, where they showed that migrant children from ethnic minorities had a high level of educational motivation and were no worse than their local peers in the same schools. Analysis of communication networks in classes shows that ethnic minorities are not discriminated against by the ethnic majority [15], [16].

At the same time, A. Soldatova's research shows that migrant children find themselves in especially difficult circumstances: they are different from the environment of a new place of residence in terms of culture. Besides, they, as a rule, come from low-income strata of society, are socially unprotected, and do not know or poorly know the language of the school system and psychology, that language relies on, so in the process of integration they risk losing their own language and cultural characteristics of their identity [17]. It is not 
difficult to predict that the emotional background of migrant children will be characterized by anxiety, disorientation, and fragmentation.

This circumstance significantly determines the state of the emotional and motivational sphere of migrant children, which, in the future, affect their success. E.V. Larskaya examines the interaction issues of the emotional sphere of schoolchildren with their educational activities. The author analyzes such concepts as "success", "a situation of success", "progress", while describing in detail the difference between subjective and objective success and offers methods for creating a situation of success in the learning activity of students by the teacher [18]. Gulyaeva's research describes a complex system of motivation in learning, which develops at primary school. It includes motives inherent in the learning activity itself, associated with its direct product: "motives relating to the content of learning"; "motives associated with the learning process" as well as motives associated with an indirect product of learning, with what lies outside the learning activity itself. The are "broad social motives, e.g. a) motives of duty and responsibility to the society, class, teacher, as well as motives of self-determination and self-improvement "narrow-minded motives, such as a) motives of well-being (the desire to get approval from teachers, parents, classmates, the desire to get good grades); b) motives of prestige (desire to be among the first students, to be the best, to take a worthy place among comrades, etc. [19].

In the context described, psychological support for the process of migrant children's adaptation in the educational environment implies the fundamental importance of positive relations between teacher and student, which is noted in the studies of Makarov, Mironova, Myazino, Omelchenko, etc. [1], [2], [3], [20].

The analysis of published works leads to the following conclusions:

Children of migrants often encounter fearful and hostile manifestations from both classmates and teachers. The reason for the ill-treatment is the large influx of migrants into Russia in recent years, which has led to an increase in social tension.

Cultural differences are reflected in ways of communication, relationship standards, values, norms and rituals of behaviour, and they often lead to misunderstandings when interacting with children and teachers at school.

It is often difficult for children of migrants to master the school curriculum, which lowers their self-esteem, negatively affects relations with others, and reduces the child's social status among peers.

The common reasons for the failure of migrant children are poor knowledge of the Russian language and poor schooling. They do not always understand the teacher's explanations, they do not know how to express their thoughts.

An important point of the work is the fact that Russian teachers lack understanding of how the image of the teacher is represented in the mind of a child of a different nationality.

\section{Materials and the results of the research}

The purpose of the empirical research is to study the motives of interaction in the studentteacher dyad.

The object of the research is professional interaction in the student-teacher dyad, and its subject is the cultural features of the teacher's motivational sphere and the motives of the cognitive development of children.

One hundred and twenty people participated in the empirical study.

Of the 30 persons who participated in the study, 30 were teachers of general education schools in Tajikistan, 30 were teachers of general education schools in Russia, 30 were students of general education schools in Tajikistan and 30 were students of general education schools in Russia. 
The color metaphor method of I.L. Solomin was chosen to study the phenomenon of motifs and relationships. In our research, the color metaphor method of I.L. Solomin was used to identify a person's motivation and integral assessment of their emotionalmotivational sphere. C. Zamfir's methods for studying the motivation of professional activity were applied to research into the motivation phenomenon. The methodology used to motivate the teaching profession reveals the internal and external motivation of teachers in their teaching activities. The school children's motivation was studied through M. V. Matyukhina's method for diagnosing a student's educational motivation structure. This technique makes it possible to diagnose the educational motivation and also to determine additional motives for learning.

The obtained results were processed in STATISTICA v.10 programme by means of such methods as cluster analysis, factor analysis and correlation analysis; $t$-test was used to assess the statistical significance of the differences.

Teachers' motives. The following hidden motives emerged from the processing of the data through the cluster analysis method.

When analyzing a cluster tree for a sample of Russian teachers, the following main clusters have been found:

The first cluster Success-To Defend Your Interests is the most relevant for the tested. Cluster indicates teachers' motivation for positive results. The second significant cluster Joy-Intimacy, includes the concepts My Present (which is the meaning-bound marker of hidden motives), Respect and Support, Joy, Education and Intimacy. These concepts are positively associated with professional activities. Presumably, the cluster reflects the actual needs of the tested.

The third cluster includes Help, My Childhood, Love, Friendly Relations, as well as Perfect and Infallible. We can assume that Russian teachers are motivated to enter into friendly contact with students, are open and responsive in helping them.

The fourth cluster My Studies - My Work includes motives of attitude to work, people around, and satisfaction of basic needs. The vast cluster can be interpreted as a positive attitude to work, to the surrounding employees and students based on positive experience of satisfied needs in the early period of life.

The fifth cluster Failure-Obedience to Force contains experiences and sources of stress. It can be assumed that teachers avoid conflict situations and displace the sources of unpleasant and painful experiences. 


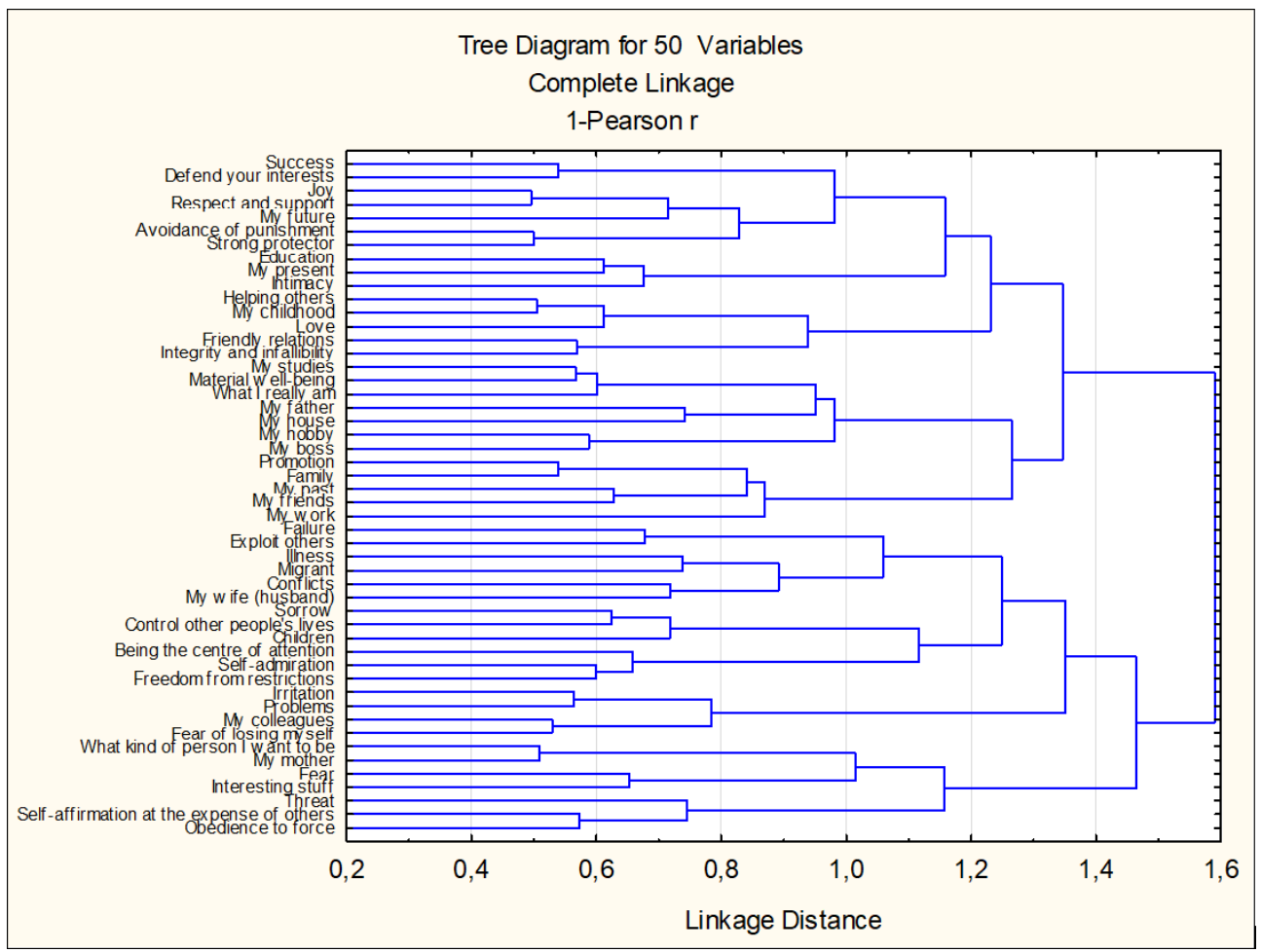

Fig. 1. Russian Teachers' Cluster Tree.

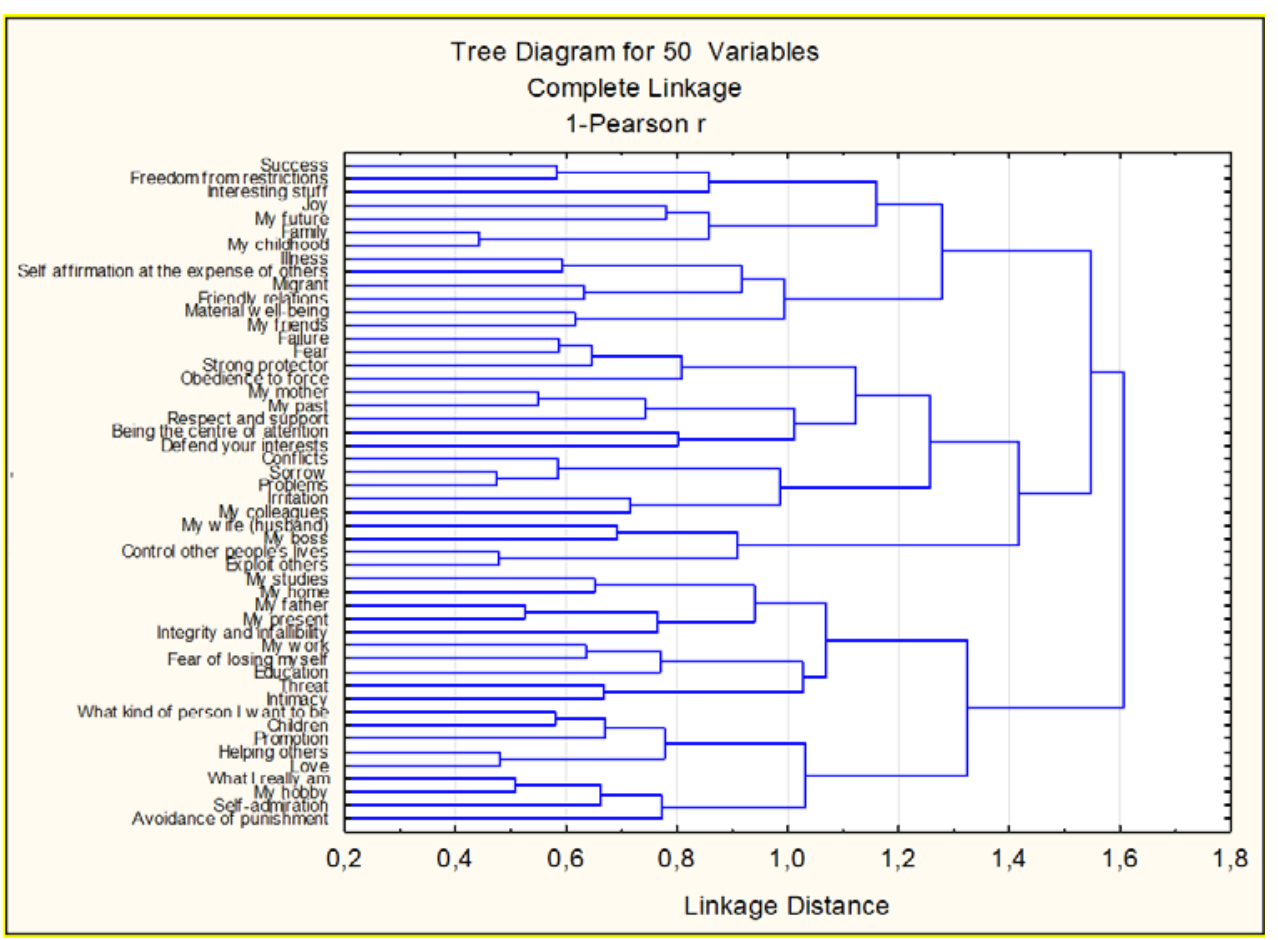

Fig. 2. Tajik Teachers' Sample Cluster Tree. 
In the analysis of the cluster tree of Tajik teachers' sample, the following main clusters stand out:

The first cluster Success - My Childhood. The cluster tree includes Exemption from Restrictions, My Childhood and My Future; consequently, it is possible to assume that the motivation of the teachers is the acquisition of meaningful social status and freedom at the expense of the teacher's position.

The second cluster Disease - My Friends includes the following descriptors: SelfAffirmation at the Expense of Others, Migrant, Friendship and Material Well-Being. It can be assumed that for the subjects the sources of stress are compensated by material wellbeing, the presence of friendships and support from friends.

The third cluster Failure - Defend Your Interests includes the following variables: Fear, Strong Protector, Obedience to Force, My Mother, My Past and Being the Centre of Attention. The cluster reflects frustration, fear, fixation on the past and the need for strong protector to successfully resolve the current stressful situation.

Cluster 4 Conflict - Exploit Others. The negative cluster variables suggest that the problems of dominance and subordination are relevant for the subjects. It is important that the mode of cooperation and mutual assistance is not visible in any of the clusters.

The fifth cluster My Study - Avoidance of Punishment contains the following variables: My Father, My Present, My Job, Fear of Losing Myself, Education, Threat, What Kind of Person I Want to Be, Children, Promotion, Helping Others, Love, "What I Really Am and My Hobby. This reflects the internal conflict of self-realization in the profession and building a career - on the one hand, and fear of punishment and failure - on the other. The cluster indicates unpleasant ulterior motives that are being pushed out of consciousness.

Results of the factor analysis. In the group of Russian teachers, factor analysis made it possible to identify 5 factors, with a total explanatory variance of $77.8 \%$.

Factor 1 Altruism - Avoidance (22.81\%) includes the descriptors To Help and My Childhood - which probably indicates the connection of altruistic motives in Russian school teachers with the positive experience of their own childhood.

Factor 2 Success-Failure (22.4\%) contains descriptors Success, My Past and, from the opposite pole - Migrant and Failure, which may indicate that the subjects have differentiated motives of success with children of migrants who are more often associated with failure.

Factor 3 Image of Me (12.19\%) contains descriptors What Kind of Person I Want to Be, My Father and Material Well-Being at one pole and Exploiting Others at the other. Thus the success of a teacher's professional activity is contrasted with the exploitation of others.

Factor 4 Basic Needs - Sources of Stress (10.4\%) contains the variables Interesting Activity, Joy and at the opposite pole Migrant and Disease. It gives rise to concerns that having migrant children is more associated with stress than joy.

Factor 5 Sources of Stress $(10 \%)$ is rather unipolar and contains the variables Self Assertion at the Expense of Others and Use of Force - here for the first time appears a theme of dominance, or more precisely, its rejection.

In the group of Tajik teachers, the factor analysis made it possible to identify 3 factors with a total explanatory variance of $62.31 \%$.

Factor 1 Satisfaction of Basic Needs" (21.51\%) contains the variables My Past and Fear of Losing Myself, i.e. fixation on the negative experience acquired in childhood. It can be assumed that teachers in Tajik schools are more focused on compensating for unsatisfied motives of childhood and to a lesser extent on the motives of professional activity of the teacher.

Factor 2 Privacy-Avoidance (20.8\%), contains the variables My Home and Calmness. So we can assume that the ulterior motives of teachers in Tajik schools are directed towards solitude and avoiding failure at the expense of being alone in a safe place. 
Factor 3 Compensation-Success (19.5\%) contains the variables Obedience to Force and Control the Others' Lives - from one pole, and Success - from the other. The analysis of this factor suggests that Tajik school teachers compensate for unpleasant experiences and achieve the desired and significant social status for them through self-assertion and control of students.

Results of the teacher motivation study. The data obtained with C. Zamfir's methods revealed differences in the internal and external motivation of Russian and Tajik teachers and showed the statistical significance of the differences.

The main motive in the pedagogical activity of Russian teachers is the educational process itself, and it is the leading activity motive. In turn, Tajik teachers have an external positive motive. It can be assumed that for Tajik teachers, the main motive in educational activities is social status and approval, the prestige of the profession, and salary.

Social approval and encouragement, the prestige of the profession is also evaluated differently by teachers of secondary schools in Russia and Tajikistan. As a motive for professional activity for teachers of Russian schools, "external positive motivation" is less important than for teachers of Tajik schools.

Results of students' motivation study. The data obtained with the help of M.V. Matyukhina's method allowed us to identify differences in the educational motivation of students.

The Cognitive Motivation criterion showed that Russian school students are more focused on the development of cognitive motivation in connection with the internal motives of the teacher. Probably, the educational activity is an end in itself for Russian teachers. In understanding this, it can be assumed that the Russian teacher establishes a connection with the student and makes him/her interested to awaken the child's cognitive activity.

The Self-Development Motivation criterion showed that students in Russian schools are more focused on self-development than Tajik students. Probably, the results are associated with the teacher's non-judgmental and altruistic motivation. In turn, Tajik teachers are more concentrated on external motives of encouragement, approval and social significance. In professional activity, the Tajik teachers' inner motives are not the main ones, which affects the educational motivation of students.

The Achievement Motive criterion showed that migrant students are more guided by the achievement motive. We tend to associate this with the schoolchildren's experience gained from teachers in Tajik schools.

The comparison of the tested groups results shows that teachers of Russian schools are motivated by the activity itself as a whole. The motivation is based on the desire to help the student in educational activities, to establish contact with him/her for the positive development of the student's cognitive motivation and active tendencies to selfdevelopment. Besides, the social significance of the profession, rewards, prestige and status fade into the background for Russian teachers. They are not relevant motives in interacting with students. For Tajik teachers, professional activity is an integral component of meeting the urgent needs for recognition and respect, for the prestige of the profession and rewards. The social assessment and the status of the profession itself are also important. Driven by external motives when interacting with students, Tajik teachers convey the importance of social approval to a greater extent, which encourages the motives of a child's achievement in educational activities to actively compete for leadership in the class. Therefore, the stimulation of cognitive motives in the teacher's professional activity fades into the background.

The comparative analysis of students in Russian and Tajik schools suggests that students in Russian schools, when interacting with a teacher, show interest in the educational process. They are focused on self-development, are open to interaction and ready for successful addressing of existing situations without a critical assessment of the 
student by the teacher. Students of Tajik schools, in interaction with the teacher, accept the translating motivations of the importance of social approval. This is manifested in the substitution of educational motivation of students for motives of achieving success. The main motivation for students in Tajik schools is emotional encouragement from the teacher.

\section{Conclusions}

The study collected and analyzed data that characterize the professional motivation of teachers of secondary schools in Russia and Tajikistan and the educational motivation of students.

The collected data showed that the motives of Russian teachers are focused on an altruistic attitude to work, while the motives of Tajik teachers are more concentrated on meeting their own needs.

The comparison of the results in subject groups shows that teachers of Russian schools are motivated by the activity itself as a whole. The motivation is based on the desire to help the student in educational activities and to establish contact with him/her for the positive development of the student's cognitive motivation and active tendencies to selfdevelopment.

For Tajik teachers, professional activity is an integral component of meeting the current needs for recognition and respect, prestige of the profession and incentives. Social assessment and the status of the profession itself are equally important.

There were also statistically significant differences in students ' learning motivation. Russian school students are motivated to study and develop themselves, while migrant students are more motivated by the experience gained from Tajik school teachers. Students of Russian schools, when interacting with the teacher, show interest in the educational process, are focused on self-development and are are open to interaction and successful solution of existing situations without critical evaluation of the student by the teacher.

Students of Tajik schools, in interaction with the teacher, accept transmitting motivations of the social approval importance, which is manifested in the substitution of students ' educational motivation for the motives of success. The main motivation for students in Tajik schools is emotional encouragement from the teacher.

Understanding how the image of a teacher is presented in the mind of a child of a different nationality, as well as an understanding of the specifics of the motivation for the cognitive development of migrant children will help Russian teachers to contribute to the successful adaptation of migrant children, to select methods and means of teaching.

It should be noted that the results of the study in no way allow us to draw conclusions about the psychological characteristics of the people of Tajikistan, they only reflect the current situation with migrant children. For a more complete interpretation of the data from the cross-cultural study, it is necessary to correlate the results with the social and economic situation in both countries and with the mentality of the people.

\section{References}

1. T.A. Mironova, Psychological support for the process of migrant children's adaptation to school, Molodoi uchenyi, 4, 659-662 (2015)

2. A.Ya. Makarov, Social and cultural adaptation of migrant children in the educational environment, access mode: http://www.dissercat.com, (access date: 19.03.2018) (2010)

3. O.Yu. Miazina, Adaptation of migrant children to the school environment, Historical and socio-educational thought: electronic journal, 2 (18), 80-83 (2013) 
4. J. Ainsworth, Sociology of education an A-to-Z guide Thousand Oaks: SAGE Publications, p. 1056 (2013)

5. M. Gordon, Assimilation in American life: the role of race, religion, and national origins, p. 272 (Oxford university press, 1964)

6. R. Alba, The children of immigrants in school: a comparative look at integration in the United States and Western Europe, p. 350 (New York university press, 2013)

7. O.I. Krushelnitskaya, Learning to live together, Nachalnaia shkola, 9, 131-135 (2003)

8. E.B. Demintseva, Migrants from Central Asia in Moscow, access mode: http://demoscope.ru/weekly/2014/0597/tema01.php (access date: 27.10.2017) (Moscow, Demoscop weekly, 2014)

9. Yu.F. Florinskaya, Migration and the labor market, p. 108 (Moscow, Publishing House Delo, 2001)

10. N.N. Maliarchuk, L.V. Krugova, Ways to overcome the difficulties of adapting migrant children to the Russian school reality, E-koncept, 37, 131-135, access mode: http://e-koncept.ru/2015/95649.htm. (access: 21.01.2018) (2015)

11. T.V. Burkovskaya, Socio-cultural adaptation of teenagers from migrant families, $\mathrm{p}$. 27 (Briansk, 2003)

12. E.A. Zhelezniakova, Migrant children in modern Russian schools: ways of language adaptation, Izvestia PSPU named after Belinsky V.G., 28, 774-778 (2012)

13. E.Yu. Zakharchenko, Migrant children in the atmosphere of a modern Russian school, access

mode:

http://portalus.ru/modules/shkola/rus_readme.php?subaction=showfull\&id=11927070

95\&archive $=1196815384 \&$ start_from $=\& u c a t=\&$ category $=3$ (access date: 17.03 .2018 ) (2007)

14. M.A. Rimarchuk, Motivation of teachers' professional activity, p. 293 (Krasnoyarsk, 2012)

15. D.A. Aleksandrov, Migrant children and parents in cooperation with the Russian school, 1, 176-199 (SPb. Polytechnic university Publishing House, 2015)

16. D.A. Aleksandrov, Ethnic composition of schools and the migration status of schoolchildren in Russia, 1, 173-195 (SPb. Polytechnic university Publishing House, 2015)

17. A. Soldatova, The experience of ethnological study of school systems in multi-ethnic megacities, p. 302 (Moscow, 2014)

18. E.V. Liarskaya, "They are odd people ...": Some stereotypical ideas of teachers of the Yamal-Nenets Okrug about tundra people, Anthropological forum, 5, 242-258 (2006)

19. A.N. Guliaeva, Socio-cultural adaptation of migrant children, Part 2, 5, access mode: https://psyjournals.ru/psyedu_ru/2010/n5/Gulyaeva.shtml (access date: 11.01.2018) (psyedu.ru, 2010)

20. E.L. Omelchenko, Yu.V. Andreeva, E.L. Lukyanova, G.A. Sabirova, Ya.N. Krupets, Adaptation of migrant children in school, p. 216 (Moscow, Ulyanovsk State University, 2010) 